\title{
SOME NEW SCALES OF REFINED JENSEN AND HARDY TYPE INEQUALITIES
}

\section{S. Abramovich, L. E. Persson And N. SAmko}

Abstract. Some scales of refined Jensen and Hardy type inequalities are derived and discussed. The key object in our technique is $\gamma$-quasiconvex functions $K(x)$ defined by $K(x) x^{-\gamma}=\varphi(x)$, where $\varphi$ is convex on $[0, b), 0<b \leqslant \infty$ and $\gamma \geqslant 0$.

Mathematics subject classification (2010): 26D15.

Keywords and phrases: Inequalities, refined Hardy type inequalities, refined Jensen type inequalities, convex functions, $\gamma$-quasiconvex functions.

\section{REFERENCES}

[1] S. Abramovich And L. E. Persson, Some new scales of refined Hardy type inequalities via functions related to superquadracity, to appear in Math. Inequal. Appl.

[2] S. Abramovich And L. E. Persson, Some new refined Hardy type inequalities with breaking points $p=2$ or $p=3$, Proceedings of IWOTA 2011, Operator Theory and Advances, Birkhäuser, to appear.

[3] G. H. HARDY, Note on a theorem of Hilbert, Math. Z. 6 (1920), 314-317.

[4] G. H. HARDY, Notes on some points in the integral calculus, LX. An inequality between integrals, Messenger of Math. 54 (1925), 150-156.

[5] G. H. HARDY, Notes on some points in the integral calculus, LXIV. Further inequalities between integrals, Messenger of Math. 57 (1928), 12-16.

[6] C. O. Imoru, On some integral inequalities related to Hardy's, Canad. Math. Bull. 20, 3 (1977), 307-312.

[7] V. Kokilasihvili, A. Meshri And L. E. Persson, Weighted norm inequalities for integral transform with product kernels, Mathematics Research Development Series, Nova Science Publishers Inc., New York, 2010.

[8] A. Kufner, L. Maligranda And L. E. Persson, The Hardy inequality. About its history and related results, Vydavatelsky Servis, Pilzen, 2007.

[9] A. Kufner And L. E. Persson, Weighted inequalities of Hardy type, World Scientific Publishing Co., Inc., River Edge, NJ, 2003.

[10] J. A. Oguntuase And L. E. Persson, Refinement of Hardy's inequalities via superquadratic and subquadratic functions, J. Math. Anal. Appl. 339 (2008), 1305-1312.

[11] J. A. Oguntuase And L. E. Persson, Refinement of Hardy's inequality for "all" p. Banach and function spaces II, Yokohama Publ., Yokohama, 2008, 129-144.

[12] J. A. OguntuAse And L. E. Persson, Hardy type inequalities via convexity - the journey so far, Aust. J. Math. Anal. Appl. 7, 2 (2010), Art. 18, 19 pp.

[13] L. E. Persson And N. SAmKo, What should have happened if Hardy had discovered this?, J. Inequal. Appl. 29 (2012), 20 pp. 